http://jmscr.igmpublication.org/home/

ISSN (e)-2347-176x ISSN (p) 2455-0450

crossref DOI: https://dx.doi.org/10.18535/jmscr/v8i10.47

Journal Of Medical Science And Clinical Research

\title{
A Clinical Study on Duodenal Perforation in Rural Medical College and Hospital
}

Authors

\section{Dr Govindaraj.A ${ }^{1}$, Dr Premkumar.T ${ }^{2}$, Dr Anvar Ali.A ${ }^{3}$, Dr Prema.M ${ }^{4}$ Dr Ravisankar.P ${ }^{5}$}

${ }^{1,}$ Post Graduate, Dept of General Surgery, Rajah Muthiah Medical College and Hospital, Annamalai Nagar, Chidambaram, India, 608002

${ }^{2}$ Assistant Professor, Dept of General Surgery, Rajah Muthiah Medical College and Hospital, Annamalai

Nagar, Chidambaram, India, 608002

${ }^{3}$ Professor, Dept of General Surgery, Rajah Muthiah Medical College and Hospital, Annamalai Nagar,

Chidambaram, India, 608002

${ }^{4,5}$ Associate Professor, Dept of General Surgery, Rajah Muthiah Medical College and Hospital, Annamalai

Nagar, Chidambaram, India, 608002

*Corresponding Author

\section{Dr Premkumar.T}

Assistant Professor, Dept of General Surgery, Rajah Muthiah Medical College and Hospital, Annamalai Nagar, Chidambaram, India, 608002

\begin{abstract}
Background: Duodenal perforation is one of the most common surgical emergency. An acute perforation is estimated to occur in $2 \%$ to $10 \%$ of patients with duodenal ulcer. Perforation is one of the important complication of duodenal ulcer. Duodenal perforation currently accounts for approximately $75 \%$ of peptic ulcer perforation. Of note, the mortality rate for perforated ulcer is high in elderly and after gastric than after duodenal perforation. ${ }^{(I)}$

Materials and Methods: The study was based on the analysis of patient admitted in Rajah Muthiah Medical College with duodenal perforation. On admission, all patient were initially resuscitated and complete history was taken and examination done followed by radiological investigation. All the findings were recorded; the information obtained was tabulated and analyzed.

Results: duodenal perforation is common in 51-60 years age group. Perforation is common in smokers and alcoholics. The overall mortality accounts to 2\%. More common in male. "O" blood group patients had higher incidence of perforation. perforation is common in low socioeconomic group. Surgical site infection was the most common postoperative complication.

Conclusion: peptic ulcer perforation is due to persistence of causative factor like alcoholism, smoking, injudicious use of NSAID, malnourishment. Incidence of perforation was more in male due to chronic alcoholism and smoking. Even in laparoscopic era, laparotomy with perforation closure is most commonly done procedure.
\end{abstract}

Keywords: Duodenal perforation, observational study. 


\section{Introduction}

The knowledge of perforation dates back to over 2000 years remote past when sushrutha the great Indian surgeon described it as parinamashula giving the relation of food, pain, vomiting. Mural to first described duodenal ulcer at autopsy in 1688. Crisp described the symptomatology of perforated peptic ulcer. Hippocrates described the face of terminal peritonitis as Hippocrates fancies since $460 \mathrm{BC}^{(2)}$. Duodenum is the first, widest and most fixed part of small intestine. It is 10 inches in length, has no mesentery and partially covered by peritoneum. The most common cause of duodenal perforation is peptic ulcer disease with life time incidence of $10 \%{ }^{(3)}$. Peptic ulcer disease is result of imbalance of acid secretion and mucosal defence mechanism. Gastrointestinal perforation constitutes the third most common cause of explorative Laparotomy as an emergency. ${ }^{(4)}$ More than $90 \%$ of patients with peptic ulcer disease are infected with H.Pylori and those not associated with H.Pylori are due to alcoholism, smoking, non-steroid antiinflammatory drugs, defective duodenal acid defense mechanism. Sudden sloughing of unsupported portion of floor of ulcer leads to perforation secondary to slow process of devascularization. Acute perforation can occur in acute and chronic duodenal ulcer. Perforation is common in anterior wall of duodenum due to spurting of gastric content on the anterior wall of duodenum.

Perforation progress in three stages:

1. Stage of peritonitis or primary stage- It occurs immediately after perforation and lasts for 6 hours. The symptoms arise due to irritation of peritoneum by escape of gastric and duodenal contents. This produces immediate reflex effect on circulatory and nervous system, commonly referred to as primary neurogenic shock.

2. Stage of reaction or secondary stage - The pain which is most intense at the moment of perforation and durning peritoneal irritation, tends to cease of at this stage due to dilution of irritants by peritoneal exudates. This stage is often referred to as stage of delusion.

3. Stage of bacterial peritonitis- pain is less severe, vomiting is frequent while hiccough may distress the patient. Due to sweating, vomiting and third space fluid loss and abdominal distention, dehydration and electrolyte depletion becomes more evident. The stage is characterized by Hippocrates fancies.

Symptoms of perforation are pain abdomen, abdominal distention, vomiting, fever. Signs include tenderness, guarding, rigidity, abdominal distention. Chest X-ray and X-ray abdomen erect demonstrates air under diaphragm. Ultrasound abdomen shows free fluid abdomen. Initially patient resuscitated followed by exploratory laparotomy. Simple perforation closure with omental patch closure is most commonly done procedure.

\section{Materials and Methods}

This is a prospective study carried out in 50 patients admitted in department of general surgery in Rajah Muthiah Medical College, Chidambaram during the period of November 2018 to February 2020.

\section{Inclusion Criteria}

All patients with duodenal ulcer perforation admitted during study period

Age 20 - 80 years

Non pregnant women

\section{Exclusion Criteria}

Age less than 20 years and above 80 years Pregnancy

All patient suspected of hollow viscous perforation were initially resuscitated with intravenous fluids and iv antibiotics in casualty and admitted in emergency ward under surgical department. Detailed history of age, sex, residence, occupation, 
socio- economic status, symptoms were recorded. History of alcohol intake, smoking, NSAID intake and co-morbidities were recorded. All routine blood investigation such as complete blood count, renal function test, blood grouping and typing, serum electrolyte, liver function test done. Ryle'S tube insertion and foley's catheterization done. After stablising, patient was sent for radiological investigation and after confirmation patient was prepared and shifted to operation theatre for exploratory laparotomy based on finding patients were segregated and patient with only duodenal perforation were taken up for study. Biopsy was taken from the edges of perforation and sent for histopathology, staining.

\section{Observation}

1. Maximum number of duodenal perforation was in the age group of 51-60 years.

2. Duodenal perforation was common males than females and male female ratio was 9:1

3. The most common etiology being acid peptic disease.

4. Alcoholics (84\%) had higher incidence of perforation when compared to nonalcoholics (16\%).

5. Smokers $(80 \%)$ had higher incidence of perforation compared to non smokers (20\%).

6. Incidence of perforation was common in low socioeconomic group followed by middle

7. Incidence of perforation was more common in cases with "o" blood group followed by "A" blood group, "B" blood group and "AB" blood group.

8. The most common symptom was abdominal pain $(92 \%)$ followed by abdominal distention (70\%), fever vomiting.

9. The most common sign was dehydration (86\%) followed by tachycardia (72\%), hypotension, pallor. This may be probably due to third space fluid loss and reduced fluid intake due to abdominal pain.

10. Duodenal perforation was most common in laborers $(44 \%)$ followed by farmers $(28 \%)$, housewife (10\%), student (10\%). This is due to stress, H.pylori infection, malnutrition and decreased mucosal resistance.

11. The commonest hematological finding was anemia followed by leucocytosis.

12. Radiologically extraluminal air was seen on x-rays in 45 (90\%) of study populations.

13. The commonest postoperative complication was surgical site infection followed by respiratory, dyselectrolytemia, burst abdomen.

14. All the duodenal perforation were seen in anterior aspect of D1.

15. 39(78\%) cases were positive on giemsa staining of biopsy specimen

16. 35(70\%) cases were positive for rapid urease test.

Table A: Mortality Rate

\begin{tabular}{|l|l|l|}
\hline Total number of cases & 50 & $100 \%$ \\
\hline No of deaths in study & 01 & $02 \%$ \\
\hline
\end{tabular}

Mortality rate $-2 \%$

Table B: Age Distribution

\begin{tabular}{|l|c|c|}
\hline Age & No of cases & Percentage \\
\hline$<20$ years & 02 & 04 \\
\hline 21-30 years & 08 & 16 \\
\hline 31-40 years & 04 & 08 \\
\hline 41-50 years & 12 & 24 \\
\hline 51-60 years & 14 & 28 \\
\hline 61-70 years & 07 & 14 \\
\hline $71-80$ years & 03 & 06 \\
\hline
\end{tabular}

Table C: Gender Distribution

\begin{tabular}{|l|c|c|}
\hline Gender & Number of cases & Percentage \\
\hline Male & 45 & 90 \\
\hline Female & 05 & 10 \\
\hline
\end{tabular}


Table D: Occupation

\begin{tabular}{|l|c|}
\hline Occupation & Number of cases \\
\hline Farmer & 14 \\
\hline Laborer & 22 \\
\hline Housewife & 05 \\
\hline Businessmen & 04 \\
\hline Student & 05 \\
\hline
\end{tabular}

Table E: Socio Economic Status

\begin{tabular}{|l|c|c|}
\hline Socio economic status & Number of cases & Percentage \\
\hline Low & 43 & 86 \\
\hline Middle & 05 & 10 \\
\hline Upper & 02 & 04 \\
\hline
\end{tabular}

Table E: Alcohol and Perforation

\begin{tabular}{|l|l|l|}
\hline Alcoholics & 42 & $84 \%$ \\
\hline Non alcoholics & 08 & $16 \%$ \\
\hline
\end{tabular}

Table F: Smoking and Perforation

\begin{tabular}{|l|l|l|}
\hline Smokers & 40 & $80 \%$ \\
\hline Non- smokers & 10 & $20 \%$ \\
\hline
\end{tabular}

Table G: Symptoms

\begin{tabular}{|l|c|c|}
\hline Symptoms & Number of cases & Percentage \\
\hline Abdomen pain & 46 & $92 \%$ \\
\hline Abdomen distention & 35 & $70 \%$ \\
\hline Fever & 26 & $54 \%$ \\
\hline Vomiting & 30 & $60 \%$ \\
\hline
\end{tabular}

Table H: Signs

\begin{tabular}{|l|c|c|}
\hline Signs & Number of cases & Percentage \\
\hline Dehydration & 43 & 86 \\
\hline Tachycardia & 37 & 74 \\
\hline Hypotension & 30 & 60 \\
\hline Pallor & 25 & 50 \\
\hline
\end{tabular}

Table I: Blood Group and Perforation

\begin{tabular}{|l|c|c|}
\hline Blood Group & Number of cases & Percentage \\
\hline O & 28 & 56 \\
\hline A & 18 & 36 \\
\hline B & 8 & 16 \\
\hline AB & 6 & 12 \\
\hline
\end{tabular}

Table J: Postoperative Complication

\begin{tabular}{|l|c|c|}
\hline Complications & Number of cases & Percentage \\
\hline Wound infection & 12 & $24 \%$ \\
\hline Respiratory & 10 & $20 \%$ \\
\hline Dyselectrolytemia & 08 & $16 \%$ \\
\hline Sepsis & 01 & $02 \%$ \\
\hline Burst abdomen & 02 & $04 \%$ \\
\hline Bed sore & 01 & $02 \%$ \\
\hline
\end{tabular}

\section{Graph-1: Giemsa Staining}

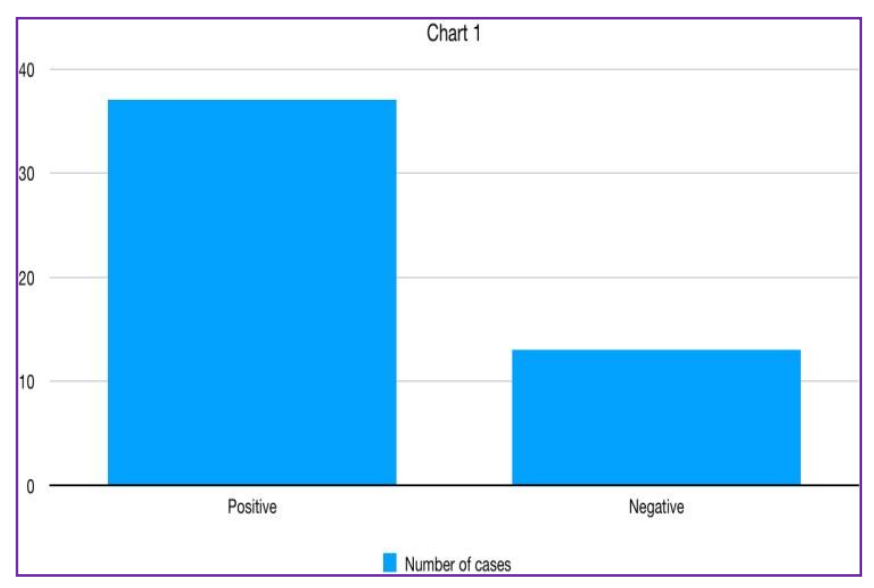

Graph-2: Rapid Urease Test

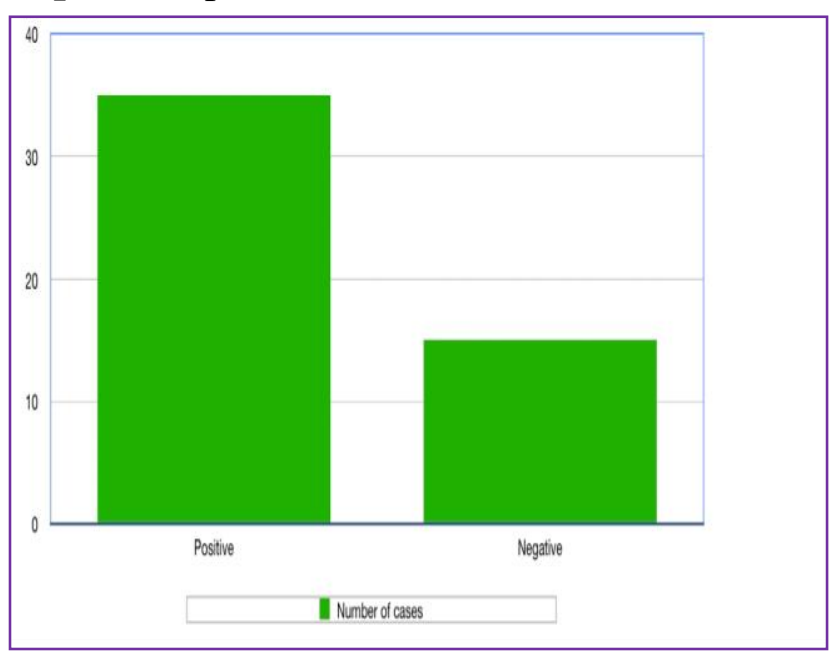

\section{Discussion}

In this study of duodenal perforation in Rajah Muthiah Medical College and Hospital in the period of July 2018- July 2020, the various etiological factors, adverse habits are taken into account and the various intra operative findings and complications of the patients are analyzed in the post operative period. These are summed up and compared with literature 
studies. Incidence of duodenal perforation was more in males compared to females in a ratio of 9:1. Elderly people were more prone for duodenal perforation than younger and middle aged. In this series, perforation was common in cases with "O" blood group followed by "A" blood group, "B" blood group and "AB" blood group. Smokers had higher incidence of perforation than non smokers. Cigarette smoking have been mainly implicated as strong independent risk factor in pathogenesis of peptic ulcer disease and its complication. ${ }^{(5)}$ The complication implicated in cigarette smoking are due to decrease healing, impairs response of healing, increases complications but the exact mechanism is not known ${ }^{(6)}$. Alcohol, tobacco and excessive smoking have been blamed as accessory cause of peptic ulcer. The influence of alcohol and tobacco in predisposing to perforation has been emphasized by author parmar $^{(7)}$ and Al-Marsoumi. ${ }^{(8)}$

Perforation was common in laborers followed farmers, housewife, student. The most common presenting complaint was abdominal pain followed by abdominal distention. The most common sign dehydration followed by tachycardia. The mortality rate was $2 \%$ due to septic shock. The most common complication was wound infection. It has been estimated that more than $50 \%$ population is infected by H.pylori infection the most important factor responsible for peptic ulcer disease, so eradication of H.pylori can reduce the incidence of perforation.

\section{Conclusion}

The incidence of hollow viscous perforation is on raise due to increase in addiction habits such as smoking, alcohol, injudicious use of non steroidal anti inflammatory drugs, malnutrition and stress. Thus, life style modification like abstinence from smoking and drinking alcohol can help reduce the disease burden.

\section{References}

1. Shackelford's surgery of alimentary tract volume 2: 823-25

2. Jeremy T. The peritoneum, omentum, mesentry and retroperitoneal space. 24th edition. In: Russel RCG, Williams NS, Bulstrode CJK. Bailey and loves's short practice of surgery. London: Arnold publisher; 2000. pg.1133-62.

3. David M. Mahvi and Seth B. Krantz., Stomach. In, Courtney M. Townsend. sbiston, Textbook of surgery the biological basis of surgical practice, 19th edition, Philadelphia, Elsevier 2012; 1191-2.

4. Kellog LC. A treatise on peptic perforation. Surgery 1939;6:524-30

5. Smedley f, Hickisht, Taubem, Yale's, Leachr, Wastell. Perforated duodenal ulcer and cigarette smoking. Jrsoc med 1988; 81:92-4

6. Bennett JR. smoking and the gastrointestinal tract . Gut 1972 658-665

7. Parmar H. Prajapati M. Shah R. Recent trends in peptic perforation. Int $\mathbf{J}$ Med sci public health 2013; 2:110-2.

8. Dalkubo JC, Naader SB, cleggy- Lemptey JN, Gastroduodenal peptic ulcer perforation East African medical Journal vol. 86 No. 3 March 2009. 